\title{
$\operatorname{arCOS} D E S I G N$
}

\section{Como a Arquitetura + Design + Urbanismo contribuem no / para o processo de (re)invenção de identidades das cidades?}

\author{
Ana Beatriz da Rocha \\ tiz.darocha@gmail.com \\ Instituição: \\ Departamento de Arquitetura e Urbanismo, \\ Escola Superior de Desenho Industrial, \\ Universidade do Estado do Rio de Janeiro (DAU/ESDI/UERJ) \\ Endereço: Rua do Passeio, ${ }^{\circ} 80$ - Centro, Rio de Janeiro - RJ
}

\section{Paulo Reis}

pauloreis@espm.br

Instituição:

Agência UFRJ de Inovação (Agência UFRJ) e Programa de Mestrado Profissional e Gestão da Economia Criativa. Escola Superior de Propaganda e Marketing (MPGEC/ESPM-Rio).

Endereço: Rua do Rosário, no 90 - Centro, Rio de Janeiro - RJ 
Como a Arquitetura + Design + Urbanismo contribuem no / para o processo de (re)invenção de identidades das cidades?

Resumo: Um dos principais aspectos das políticas de transformação urbana é a (re)invenção das cidades através do (re)desenho de suas áreas vazias, onde novas arquiteturas e a (re)ordenação dos espaços públicos degradados visam alterar a imagem do lugar. O intuito aqui é discutir como estes processos "regeneradores" poderiam se utilizar de ideias, estratégias e/ou conceitos "inovadores" conectando, de forma consistente e integrada, a Arquitetura, o Design e o Urbanismo - tornando-os instrumentais na proposição de políticas urbanas mais colaborativas, participativas, solidárias e sustentáveis.

Palavras-chave: Cidade; imagem; identidade; consumo; inovação urbana.

\title{
How Architecture + Design + Urbanism contribute towards/ to the process of the (re)invention of cities' identities?
}

\begin{abstract}
One of the main aspects of urban regeneration politics is the (re)invention of cities through the (re)design of their wastelands, where new architectures and the spatial (re)organisation of derelict public spaces intend to alter the image of the place. The intention here is to discuss how these "regenerative" processes could use "innovative" ideas, strategies and/or concepts connecting, in a consistent and integrated way, Architecture, Design and Urbanism - making them instrumental in the proposition of more collaborative, participative, solidary and sustainable urban policies.
\end{abstract}

Keywords: City; image; identity; consumerism; urban innovation 


\section{Introdução}

As discussões levantadas no seminário "DESIGN.COM: articulações, expansões, conexões" ${ }^{1}$ - sobretudo nas sessões "Campos, fronteiras, articulações" (2016) e "Expansões do Design: possíveis 'comuns' urbanos" (2017) - indicaram que novas (e possíveis) trocas de experiências, fazeres e saberes são absolutamente fundamentais para a elaboração de novas (e possíveis) formas de intervenção no espaço urbano. Tendo como base a ideia de que processos de regeneração urbana são fortemente calcados na transformação (física e simbólica) de áreas degradadas e na criação de novas identidades para as cidades, este artigo tem como principal tema a discussão sobre como a Arquitetura, o Design e o Urbanismo podem ser instrumentais na proposição de políticas urbanas mais colaborativas, participativas, solidárias e sustentáveis.

Políticas de transformação urbana promovem uma completa ressignificação dos espaços públicos que, aliados à inserção de arquiteturas espetaculares, passam a ser identificados como "bens de consumo", avidamente consumidos por um público cada vez maior e mais diversificado. Um dos principais aspectos deste fenômeno é a (re)invenção das cidades através do (re)desenho de suas áreas vazias, onde novas arquiteturas (espetaculares) e a (re)ordenação dos espaços públicos degradados visam alterar a imagem do lugar. Entretanto, em contraste ao "modelo Barcelona" 2, constantemente implementado em diversas cidades ao redor do mundo, o relatório da ONU (2014) prevê que, em 2050, 6 bilhões dos 9 bilhões de habitantes do mundo morarão em cidades aumentando ainda mais as demandas por serviços básicos como saneamento, transporte, moradia, fornecimento de eletricidade e água potável, coleta de resíduos, oferta de vagas em escolas, creches e hospitais e provisão de moradia, dentre outros.

\footnotetext{
${ }^{1}$ Seminário promovido pelo Laboratório de Design e Antropologia da Escola Superior de Desenho Industrial, Universidade do Estado do Rio de Janeiro (LaDA/ESDI/UERJ)

O "modelo Barcelona" - composto de uma série de ações planejadas conjuntamente, incluindo provisão de equipamentos culturais, desenvolvimento de políticas culturais e urbanas integradas, e transformação de áreas (centrais) degradadas - foi consequência do relativo êxito na implementação do (longo) projeto de reestruturação urbana que transformou a cidade para receber as Olimpíadas de 1992. Após o sucesso de público no evento, que ajudou a consolidar a cidade como um destino turístico de massa, cidades pós-industriais no mundo inteiro recorreram ao "modelo Barcelona" para "regenerar" suas áreas (sobretudo centrais, históricas, portuárias) degradadas (Balibrea, Mari Paz, 2001, pp 187-210 e Dodd, Dianne, 2004, pp 177-182).
} 
Neste cenário fica clara a necessidade de se repensar, equilibrar e promover ajustes nas estruturas que moldam os centros urbanos - uma vez que o modelo atual de urbanização e de consumo dos espaços criam enclaves socioeconômicos e estimulam o aumento das desigualdades sociais, além de promover um sistema de especulação imobiliária e fundiária incessante. Considerando este cenário, assim como as discussões levantadas durante o seminário DESIGN.COM e as ideias surgidas no desenvolvimento da pesquisa "Arquitetura + Design + Cidade" ${ }^{3}$, percebe-se o quão crucial é propor equipamentos, formas, processos, sistemas e organismos que, mesmo oriundos de uma estrutura urbana consolidada e orientados para o consumo da cidade como "espetáculo", possam configurar-se como "inovações urbanas".

Mas o que seriam inovações urbanas?

- Inovações urbanas

Inovações urbanas são ações/interações coletivas e/ou interinstitucionais que buscam, de forma efetiva, contribuir para a transformação dos espaços, das pessoas, das instituições, das políticas e das estruturas de uma cidade/sociedade. Estas ações/interações visam a elaboração de políticas públicas e de práticas de intervenção com potencial para criar serviços integrados e inteligentes - o que, segundo Nonaka e Takeuchi (1997), permite redefinir problemas e repensar soluções, além de incentivar a adaptação em ambientes em constante transformação.

Villa e Mitchell (2010) sugerem que as inovações urbanas têm complexidades diversas como: criação de serviços integrados de cidadania e de soluções "verdes" (transporte, energia, construção, etc..); desenvolvimento de subsídios para impulsionar a criação de redes para o provimento de serviços focados na melhoria da qualidade de vida e sustentabilidade ambiental; criação de parcerias para incentivar a "inovação" (social, ambiental, econômica) entre os diversos setores (governamental, sociedade civil, empresariado) presentes em comunidades urbanas, etc.. Já o World Economic Forum (Global Agenda Council on the Future of Cities, 2015) indica alguns princípios que norteiam o conceito de "inovação urbana”, incluindo:

- usar recursos existentes subutilizados

\footnotetext{
${ }^{3}$ Pesquisa interdisciplinar e interinstitucional desenvolvida pelos autores, que visa explorar como a inter-relação entre a Arquitetura, o Design e o Urbanismo pode ajudar na adoção de alternativas mais sustentáveis, solidárias, participativas e na elaboração de politicas urbanas mais justas e equilibradas.
} 
- partilhar o espaço público-privado

- ativar a economia circular; incentivar a reutilização e reciclagem

- tornar os espaços mais "verdes" (plantio de espécies vegetais) e sustentáveis

- mobilizar indivíduos; promover práticas focadas no usuário/cidadão (com idades, habilidades e modos de vida diversos)

De acordo com estes princípios, ações que promovam uma interrelação entre soluções/inovações tecnológicas, adoção/adaptação de políticas públicas e o envolvimento da sociedade civil e de instituições (públicas e/ou privadas) tendem a criar (a curto, médio e longo prazos) um impacto positivo e visível nos espaços citadinos. Há de se estimular, sobretudo, o envolvimento da sociedade civil (via ativismo e mobilização) na elaboração e implementação de ações que tenham um impacto mais imediato no dia-a-dia das pessoas. Estas ações, nas esferas micro (relações interpessoais) e/ou macro (políticas públicas), devem ser propostas simultaneamente, de forma complementar e interligada, na tentativa de equalizar duas vertentes: os anseios e reivindicações dos cidadãos, e as aspirações e "legados" dos políticos.

É importante analisar como estas duas vertentes, muitas vezes autoexcludentes, podem fazer parte de um processo de transformações físicas e simbólicas do espaço urbano - onde a Arquitetura, o Design e o Urbanismo sejam efetivamente utilizados como instrumentos, como alternativas para a implementação de políticas públicas mais inclusivas e interativas. Neste sentido, projetos colaborativos se tornam imprescindíveis, uma vez que o intuito é juntar experiências, fazeres e saberes diversos.

No entanto, tais formas de colaboração/interação encontram sérios entraves na fase de tomada de decisão - uma vez que, geralmente, especialistas tendem a liderar estas etapas, criando sentimentos de desconforto e desprestígio para os co-criadores (muitas vezes nãoespecialistas). Co-criar é um processo, nem sempre linear e/ou sequencial: necessita de regras e de gerenciamento de potenciais conflitos - sobretudo por lidar com grupos heterogêneos, normalmente sem entendimento de lógica projetual. Ou seja: é fundamental ter uma estruturação clara de como se dará esta colaboração e participação - o pressuposto é que o processo projetual seja desenvolvido com participantes (stakeholders) de diferentes níveis, com expectativas e envolvimentos diversos.

O diagrama abaixo (figura 1) indica, de forma sintética, a identificação destas possíveis formas de atuação: à esquerda apresentam-se 
as dinâmicas de interação dos stakeholders e suas respectivas formas de integração com o todo; já à direita estão os campos temáticos dos “decisores” que, na interação com os stakeholders, conduzem e conformam o projeto. Os resultados oriundos destes grupos de interação levariam, em seguida, às etapas de tomada de decisão.

\begin{tabular}{|c|c|}
\hline $\begin{array}{l}\text { pessoas conectadas } \\
\text { parceiros engajados }\end{array}$ & $\begin{array}{c}\text { arquitetos, designers } \\
\text { e urbanistas }\end{array}$ \\
\hline $\begin{array}{l}\text { expressão da situação } \\
\text { com perspec1va par1cular }\end{array}$ & $\begin{array}{l}\text { faseamento das } \\
\text { etapas de projeto }\end{array}$ \\
\hline $\begin{array}{c}\text { geração de dados macro } \\
\text { ambientais e mul1 perspec1vas }\end{array}$ & $\begin{array}{l}\text { mapa de interesses } \\
\text { dos stakeholders }\end{array}$ \\
\hline \multicolumn{2}{|c|}{$\begin{array}{c}\text { desenho de cenário situacional } \\
\text { contextualização }\end{array}$} \\
\hline $\begin{array}{l}\text { diálogo entre stakeholders com } \\
\text { perspec1va de compar1lhamento }\end{array}$ & $\begin{array}{l}\text { plataformas de diálogo } \\
\text { sinergia e troca }\end{array}$ \\
\hline $\begin{array}{l}\text { determinação hierárquica } \\
\text { de obje1vos e metas }\end{array}$ & $\begin{array}{l}\text { integração informacional } \\
\text { e tomada de decisão }\end{array}$ \\
\hline \multicolumn{2}{|c|}{$\begin{array}{l}\text { a1 vidades, metas } \\
\text { e entregáveis }\end{array}$} \\
\hline $\begin{array}{l}\text { ferramentas de integração } \\
\text { tecnologias de comunicação }\end{array}$ & $\begin{array}{l}\text { declaração do problema de } \\
\text { projeto e aprofundamento }\end{array}$ \\
\hline $\begin{array}{l}\text { par1cipação, colaboração, } \\
\text { diversidade e mul1 plicidade }\end{array}$ & $\begin{array}{l}\text { localização dos gargalos } \\
\text { iden1ficação das causas }\end{array}$ \\
\hline $\begin{array}{l}\text { esclarecimento da situação } \\
\text { seus atores e fatores }\end{array}$ & $\begin{array}{l}\text { complilação, síntese } \\
\text { e adaptação responsiva }\end{array}$ \\
\hline $\begin{array}{l}\text { ques1onamentos e } \\
\text { crí1cas e hipóteses }\end{array}$ & $\begin{array}{l}\text { iden1ficação das causas } \\
\text { relacionando com efeitos }\end{array}$ \\
\hline $\begin{array}{l}\text { propostas de ação, sugestão } \\
\text { de fases e con } 1 \text { ngências }\end{array}$ & $\begin{array}{l}\text { benchmarks e referências } \\
\text { especialistas e acadêmicos }\end{array}$ \\
\hline $\begin{array}{l}\text { definição dos obje1vos } \\
\text { compar1lhados }\end{array}$ & $\begin{array}{l}\text { avaliação, ponderação, análise e } \\
\text { estruturação do escopo de projeto }\end{array}$ \\
\hline $\begin{array}{l}\text { desenvolvimento de ações } \\
\text { incrementais e funcionais }\end{array}$ & $\begin{array}{c}\text { declaração do problema } \\
\text { aprofundamento e realidade }\end{array}$ \\
\hline \multicolumn{2}{|c|}{$\begin{array}{c}\text { implementação, entrega, } \\
\text { e monitoramento }\end{array}$} \\
\hline
\end{tabular}

Figura 1. simulação de etapas e fases sistêmicas de interação em projetos interativos/participativos (fonte: os autores) 
Esta lógica - de interação entre equipes, estratégias, culturas comportamentais, processos, valores, interesses, intenções e perspectivas distintas - se alinha ao conceito de gestão do conhecimento (Davenport, 1998; Nonaka e Takeuchi, 1997), pois sugere que os sistemas de transmissão de conhecimento - de tácito para explícito - devam ser conduzidos com parcimônia e em busca permanente da consistência e do consenso. Nesse sentido, a lógica do diálogo (Bohm, 1996) é aplicada quando se propõe a coparticipação e a exposição das posições e ponderações previstas em cada etapa.

Mas como se daria a implementação destas ações e/ou práticas "inovadoras" no processo de transformação das cidades?

\section{- Inovações ou Transformações Urbanas?}

Muitas destas ações e/ou práticas "inovadoras" são direcionadas para resolver problemas e/ou buscar soluções para mobilidade, consumo eficiente de energia, melhoria das/nas políticas de segurança e moradia, etc.. Estas ações incluem: compartilhamento e integração de sistemas (alternativos) de transporte; monitoramento e controle inteligente do trânsito e de serviços públicos; incentivo à "adoção" de áreas e de edifícios públicos (incluindo plantio de mudas e manutenção); provisão de serviços via sistemas inteligentes (smartphones), dentre outras formas de interação entre os diversos setores da sociedade.

Entretanto, muitas destas ações e/ou práticas indicam uma interdependência significativa entre inovações de cunho essencialmente tecnológico e a adoção e/ou adaptação de políticas urbanas - cujos impactos (físicos e simbólicos) se dão em diversos níveis da vida citadina. Por exemplo: os centros de operação integrados, que monitoram o trânsito e os serviços emergenciais, são inovações bastante dependentes da tecnologia de gerenciamento de dados, mas que, por outro lado, não causam um grande impacto na conformação do tecido urbano das cidades. Já o "ativismo verde”, que incentiva o plantio em áreas públicas degradadas e se utiliza da tecnologia de compartilhamento de dados, ainda que em menor escala, é uma forma de atuação e/ou transformação no meio urbano cujo impacto é bem mais significativo.

Mas como ações e/ou práticas inovadoras e/ou transformadoras se relacionam com o consumo, com a organização da vida quotidiana e a criação de estilos de vida e identidades? 


\section{Transformações Urbanas e a Mudança de Identidade das Cidades}

Em estudos anteriores ${ }^{4}$, discutiu-se como a implementação de políticas públicas de regeneração urbana em áreas históricas e/ou centrais e/ou portuárias degradadas levou a criação de um "modelo" - tendo o caso de Barcelona como exemplo mais notório. Estas políticas, de caráter impositivo ("top down"), se baseavam na criação de lugares espetaculares, de grande apelo estético e midiático, fortemente dependente de vultuosos incentivos fiscais, verbas governamentais e de parceiras público-privadas para a execução, implementação e manutenção destes espaços "revitalizados". Efetivamente, esta ressignificação dos espaços públicos levou a reinvenção da imagem das cidades - o que Harvey (1989) e Vaz (2004) indicam ser sintomáticos de processos regeneradores cíclicos e subsidiados pelo "mercado".

Com a crise mundial em 2008, os subsídios para se investir nestes projetos urbanos e arquitetônicos espetaculares, assim como na constante oferta de programações de cunho cultural, ficaram mais escassos. O turismo, a gentrificação e a especulação imobiliária nestas áreas revitalizadas também sofreram o impacto da recessão econômica - que levou, consequentemente, a uma gradual perda de investimentos para manter estas áreas atrativas e vibrantes, tanto para visitantes quanto para moradores. Por outro lado, por serem oriundas de políticas de especulação, de caráter impositivo, a maioria destas áreas revitalizadas se tornaram enclaves exclusivos para uma parcela da sociedade que pode arcar com os custos de se viver ali. Esta ausência de "diferenças" (de classes sociais, modos de vida, perfis socioeconômicos, etc..) induz a uma apropriação dos espaços, de forma mais contundente e homogênea, por um determinado segmento social. Assim, o que se vê em cidades tão diversas como Barcelona ou Berlim, por exemplo, é uma série de espaços públicos e arquiteturas muito similares, cujo público-alvo é aquele que pode pagar por certos luxos e que consome a cultura local (se é que ainda existe) sob forma de commodities.

Mas como transformações urbanas poderiam se valer de ações e/ou práticas de inovação urbana para "revitalizar" as cidades?

- Arquitetura, Design e Urbanismo como ferramentas de inovação e transformação das cidades

\footnotetext{
${ }^{4}$ da Rocha; Reis, 2012, 2015 e 2017; da Rocha e Silva, 2011.
} 
Ainda que a reestruturação de espaços públicos seja um dos principais vetores para a transformação física e simbólica de lugares degradados, é importante perceber que a revitalização de uma região não é feita apenas de grandes gestos arquitetônicos e urbanísticos. Segundo Jacobs (1961), deve-se olhar mais para a "vida real" nas cidades, para suas particularidades e dinâmicas próprias - ao invés de simplesmente replicar "fórmulas de sucesso", que tendem ao fracasso justamente por serem homogeneizantes.

Neste sentido, um dos exemplos com ações e visões bastante contraditórias sobre processos de regeneração urbana é a Operação Porto Maravilha, no Rio de Janeiro. Inicialmente idealizada como uma das grandes apostas para as Olimpíadas Rio-2016, e que serviria como impulso para o processo de revitalização da zona portuária da cidade, a operação consorciada responsável pelo "projeto" teve como principal foco a transformação física e simbólica (identidade) de uma área que vem passando por um gradual processo de esvaziamento, típico das economias pós-industriais, desde dos anos 1960. Na verdade, desde os anos 1980, uma série de estudos, projetos e ações foram desenvolvidos com o intuito de "regenerar", "requalificar" e "revitalizar" não só o espaço urbano, mas também o rico, ainda que negligenciado, patrimônio material e imaterial da região - visto que abriga uma parcela significativa da história da diáspora Africana na cidade e no Brasil. ${ }^{5}$

Nos anos 2000, propostas de revitalização urbana para a região portuária da cidade - como o Museu Guggenheim na Baía de Guanabara, projeto de Jean Nouvel - seguiam os parâmetros dos processos de transformação de Barcelona e de Bilbao, nos anos 1990. Entretanto, ainda que completamente independente e distante da proposta inicial de transformação física da região - e talvez como forma de equalizar as demandas contemporâneas relativas à visibilidade e legitimidade de processos de regeneração urbana "de baixo para cima" (bottom up) -, ritos, tradições, culturas e histórias locais foram sendo gradativamente apropriados e incorporados ao discurso do "projeto" Porto Maravilha.

Esta transformação se deu, basicamente, por dois motivos: o primeiro, econômico, tendo em vista que a crise mundial de 2008 afetou, ainda que tardiamente, a oferta de investimentos e incentivos fiscais no país; o segundo, de ordem cultural, levou a um resgate, também tardio, da importância e relevância da diáspora Africana na formação da identidade

\footnotetext{
${ }^{5}$ Estas políticas urbanas foram discutidas em da Rocha, Ana Beatriz; Reis, Paulo, 2017
} 
cultural carioca e brasileira. Com isso, elementos característicos do local foram incorporados aos discursos oficiais e transformados em políticas públicas culturais e urbanas (https://oglobo.globo.com/rio/pequena-africaroteiro-em-homenagem-ao-continente-ganha-novas-atracoes-18964630) onde a criação de um "Circuito Histórico e Arqueológico da Celebração da Herança Africana” visa resgatar elementos históricos importantes, outrora esquecidos.

O "projeto" Porto maravilha contou com as usuais práticas de revitalização urbana, incluindo o Museu de Arte do Rio (Bernardes + Jacobsen Arquitetura, 2013) e o Museu do Amanhã (Santiago Calatrava, 2016), na Praça Mauá; as conversões de armazéns industriais antigos, como o Aquário Municipal e o Armazém da Utopia, na Gamboa; a construção de edifícios de uso corporativo; a provisão de melhorias na infraestrutura (com a abertura da via Binário do Porto e dos túneis Rio 450 anos e Prefeito Marcello Alencar, a implementação de linhas de VLTs, a demolição do Viaduto da Perimetral e a criação do Boulevard Olímpico e da Orla Conde); e a proposta de reestruturação de usos, formas e funções de estruturas industriais e também do espaço urbano circundante.
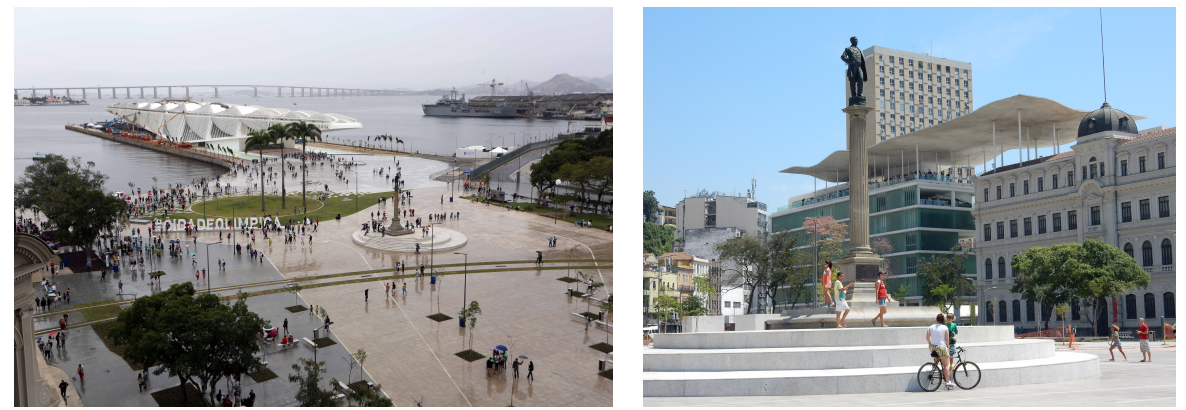

Figuras 2-3: a "revitalizada" Praça Mauá - vistas do Museu do Amanhã (à esquerda) e do Museu de Arte do Rio (à direita)
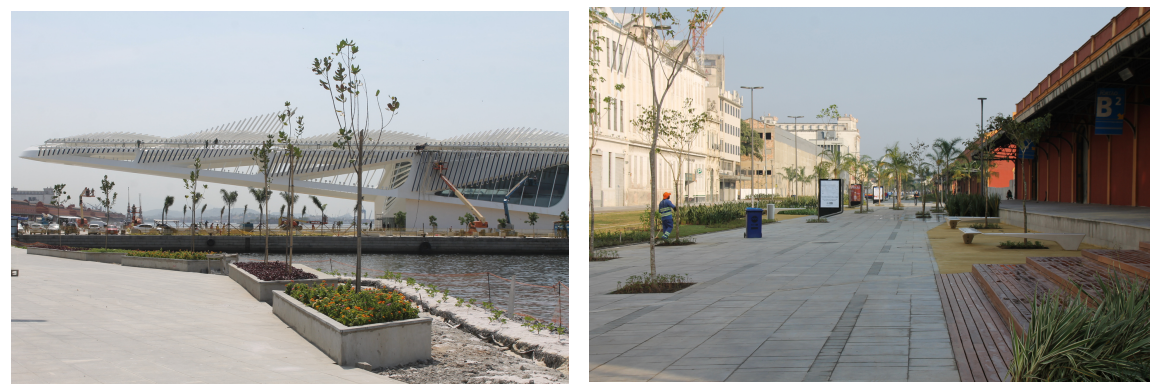

Figuras 4-5: os "novos" espaços urbanos: a Orla Conde (à esquerda) e o Boulevard Olímpico (à direita)

Fonte: os autores

Apesar destes "grandes gestos" arquitetônicos e urbanísticos, iniciativas e ações de caráter inovador e transformador vêm sendo 
propostas por ativistas culturais e empreendedores sociais atraídos pela "singularidade", "cultura", "efervescência" e pelo "mix" de gente, de gostos, de credos, de usos e de atividades existentes na região. Políticas oficiais de ocupação e de transformação do espaço urbano - cujo foco são os turistas e a circulação de capital - coexistem com uma série de atividades de conscientização (ambiental, cívica, cultural e urbana) promovidas por pessoas comuns para pessoas comuns. Neste sentido, formas de participação da coletividade na adoção e posterior organização de espaços públicos inusitados (degradados ou não) podem ser instrumentos efetivos $\mathrm{e}$ fundamentais para o "desenho" e a produção de ambientes públicos mais inclusivos e sustentáveis.

\section{Inovação e transformação das cidades - para quem?}

No Boulevard Olímpico, existem duas obras interessantes nas paredes dos antigos armazéns que exemplificam duas vertentes de uma mesma iniciativa e que visam a inovação/transformação urbana - ainda que tenham propostas bastante diferenciadas. O mural "Etnias", do artista baiano Toz, foi comissionado pela Prefeitura do Rio de Janeiro para celebrar as Olimpíadas Rio-2016 - se tornando parte do "espetáculo" do Porto Maravilha. Em contraponto, o artista parisiense JR optou por desenvolver um projeto colaborativo/participativo, onde pessoas comuns ajudaram a criar um mural efêmero ("Inside Out" - http://www.insideoutproject.net/rio2016/en/). Em 2008-2009, JR desenvolveu um outro projeto participativo/colaborativo na parte menos "espetacular" da zona portuária, onde grandes painéis com imagens dos moradores da comunidade local foram colados nas escadarias e casas do Morro da Providência ("Women are heroes" - http://www.jrart.net/projects/women-are-heroes-brazil).

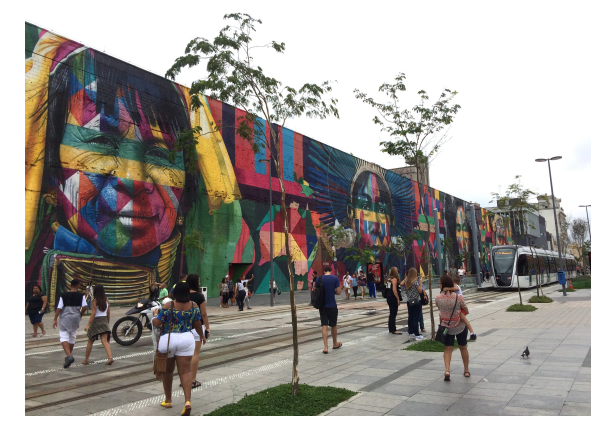



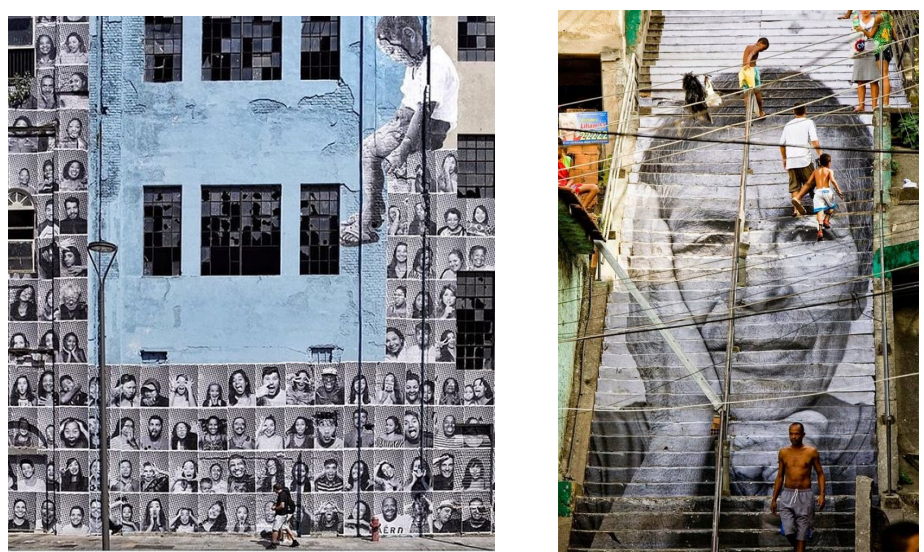

Figuras 6-8: imagens "inclusivas" no Boulevard Olímpico - o mural "Etnias", de Toz (no topo), e o painel com fotografias de pessoas comuns, parte do projeto "Inside Out", do artista JR (à esquerda); já nas escadarias do Morro da Providência, o mural do artista JR, parte do projeto "Women are Heroes" com moradores locais (à direita) fonte: os autores

O mural "Etnias", de Toz - assim como vários outros no Boulevard Olímpico -, foi resultado de um processo de transformação física do espaço imposto por políticas públicas de regeneração urbana (top down); já o mural/instalação do artista JR foi resultado de um ativismo social (botton up) que pretendia dar mais visibilidade às pessoas comuns e àquela comunidade. Ainda que a transformação urbana seja, em ambos os casos, algo perceptível, pois as intervenções artísticas contribuíram para uma requalificação e ressignificação de espaços públicos ora degradados, a inovação urbana - que pode ser traduzida no envolvimento de uma comunidade na elaboração e posterior adoção da intervenção/mural como o "retrato" de sua realidade - é verificada apenas no exemplo no Morro da Providência.

Um outro contraste interessante é relativo a localização: o mural "Etnias" e a intervenção "Inside Out” estão localizados no Boulevard Olímpico, uma área essencialmente turística e, portanto, com apelo visual e projeção nas mídias muito maiores que a outra intervenção, "Women are Heroes”, localizada nas escadarias do Morro da Providência, uma área residencial, pobre e, de certa forma, "invisível". Cabe lembrar que a zona portuária do Rio de Janeiro é caracterizada pela sua história de contrastes: do comércio pulsante (de escravos, inclusive), ainda no século XVIII; às origens das favelas, no século XIX; às transformações urbanas do início do século XX: às décadas de abandono entre os anos 1950-1970; às políticas de intervenção urbana de cunho historicista, nos anos 1980-1990; às atuais 
propostas de regeneração urbana espetaculares - todas estas fases passaram por um processo de ressignificação da ambiência e da identidade da região. ${ }^{6}$

Mencionou-se anteriormente a necessidade de se repensar, equilibrar e promover ajustes nas estruturas que moldam os centros urbanos e de se estimular o envolvimento da sociedade civil na elaboração e implementação de ações que tenham um impacto mais imediato no dia-a-dia das pessoas. Entretanto, para que estas ações sejam possíveis é necessário promover um ambiente propício a estas interações - onde as pessoas se sintam parte destes lugares, onde possam contribuir ativamente com as mudanças materiais e imateriais destes microcosmos. Neste sentido, o esvaziamento (habitacional, de pequenos comércios locais, de uso dos espaços urbanos) pelo qual a zona portuária vem passando desde os anos 1980, tem contribuído significativamente para fragilizar estes laços, para enfraquecer estes sentimentos de coletividade e de pertencimento.

Uma das alternativas previstas no "projeto" Porto Maravilha para amenizar este problema de esvaziamento urbano era implementar uma política de regulamentação fundiária e de incentivos fiscais para construção de moradias. $O$ intuito era promover um ambiente próspero de investimentos e negócios, onde as novas políticas de especulação imobiliária para a região geraria dividendos que, por sua vez, seriam aplicados na manutenção dos espaços públicos revitalizados e dos edifícios históricos além de permitir uma reocupação do centro como lugar de moradia para classes sociais diversas. Contudo, com a crise fiscal e econômica, as iniciativas que pretendiam estimular novos empreendimentos habitacionais não saíram do papel - gerando críticas às políticas urbanas que focam apenas nos aspectos turísticos da região, em detrimento ao processo de revalorização do centro como área residencial.

Uma destas políticas de valorização do turismo em detrimento às necessidades das populações locais foi a decisão (por ora "em suspenso") de burocratas e autoridades competentes em instalar mais de 50 quiosques na Orla Conde ${ }^{7}$ - frente marítima que liga o Museu do Amanhã, na Praça Mauá, à Praça XV -, tendo como base o "sucesso" dos quiosques da orla da Zona Sul carioca ${ }^{8}$. Esta decisão se deu, em parte, pela dificuldade em manter

\footnotetext{
${ }^{6}$ Giannella, 2013; Guimarães, 2014.

${ }^{7}$ O desenho da Orla Conde e do Boulevard Olímpico segue a tendência de se pensar e promover espaços públicos para fins meramente turísticos. A inexistência de áreas de sombra ou de áreas de estar (bancos, mesas, espaços para recreação infantil, etc..) acaba qualificando estes lugares como "de passagem" e não como "de contemplação", levando a um determinado tipo de uso do espaço urbano (turístico e de passagem) em detrimento a apropriação destes lugares pelas comunidades locais.

${ }^{8}$ O Globo, 2016; da Rocha; Reis, 2013
} 
a mesma efervescência na região portuária - uma vez que, com a crise atual, as políticas públicas e incentivos fiscais (Governamentais ou não) foram bastante reduzidos. Seguindo esta "lógica" que privilegia o turismo, a instalação dos novos quiosques seria, portanto, a "solução" para o problema. $\mathrm{Na}$ verdade, há uma grande dificuldade em entender as particularidades, as carências, as potências da região portuária, que se mostra viva e capaz de "se reinventar”, especialmente em um momento pós-euforia com as Olimpíadas - uma vez que problemas de ordem pública e urbana reapareceram após serem "maquiados" durantes os mega-eventos.

Segundo Guimarães (2014), a construção do imaginário coletivo pelas mídias (sobretudo depois do relativo "sucesso" de público alcançado com a Copa do Mundo FIFA, em 2014, e particularmente durante as Olímpiadas Rio-2016) reforçam o caráter cosmopolita e gentrificado da região portuária do Rio de Janeiro pois, ao invés de retratar a pobreza, a miséria, a violência, os morros e as favelas, as narrativas predominantes se utilizam dos ritos, das tradições, das histórias e culturas locais como atributos positivos e característicos (i.e. "exóticos”) do lugar. Contudo, passada a euforia com os mega-eventos (e a circulação gentes e de capital estrangeiro), a realidade é que estes espaços re-significados precisam ser "adotados" pelas comunidades locais para sobreviver. Sendo assim, a importância do ativismo social e do engajamento das populações locais é imensa, uma vez que os investimentos tendem a desaparecer logo após as cerimônias de encerramento destes grandes eventos. Ainda que parcerias público-privadas possam suprir, de certa forma, os incentivos fiscais e investimentos de grande porte, são as pequenas ações, do dia-a-dia, envolvendo as comunidades e sem muito apoio da mídia, que promovem mudanças significativas no lugar.

\section{Conclusão}

Dentre as diversas ideias surgidas nas sessões do seminário DESIGN.COM e no desenvolvimento da pesquisa Arquitetura + Design + Cidade talvez a mais perturbadora seja a que cidades pensadas apenas como uma empresa, produto, "marca" (brand) ou negócio passam a ter os mesmos atributos e as mesmas características e necessidades de planejamento, investimento e sistematização funcional que as organizações industriais e/ou comerciais e/ou institucionais. Este entendimento da cidade como algo essencialmente corporativo (e lucrativo) leva a implementação de processos 
hierarquizantes/normativos/homogeneizantes do espaço urbano, visando enfraquecer as comunidades locais e fragilizar as noções de cidadania, coletividade e pertencimento.

Por outro lado, a aplicação de técnicas oriundas do design, da publicidade e do marketing no processo de "desenho" das cidades se dinamiza no mesmo ritmo, fluidez e dinâmica que se dá a competição globalizada. Na busca pela conquista e manutenção de fatias do mercado global, as cidades precisam se reinventar constantemente - o que leva ao questionamento de como os atributos (sociais, culturais, ideológicos, etc..) de um local são manipulados e/ou modificados com o intuito de causar um impacto significativo na atração de turistas, investimentos, instituições, corporações e pessoas. Se processos de regeneração urbana funcionam apenas como um "dispositivo de marketing" para a cidade, a paisagem urbana “(...) funciona como um trunfo no concurso mundial por status, investimentos estrangeiros, megaeventos e dólares de turistas" (Scott, 2012, p. 32). A espetacularização ao extremo tende a não dar muito espaço para o significado, uma vez que, com a tendência à mercantilização dos espaços da cidade, ações transformadoras e/ou inovadoras tendem, também, a ter um caráter cada vez mais espetacular e efêmero.

O processo de construção de identidades se sustenta em legítimas traduções dos elementos de uma determinada cultura. A gestão desse sistema, para ser autêntico e consistente, deve se dar com base em narrativas urbanas e políticas de representação. Quando esse sistema de construção de identidade se faz com base em elaborações e articulações artificiais, forçadas e impostas, ele só será mantido com uma intensa e permanente aplicação de recursos financeiros e intermináveis planos de comunicação/divulgação. Portanto, a construção de identidades baseada nos valores, atributos e características legítimas e reais dos lugares leva à um processo de manutenção destas particularidades, sobretudo se proporcionar oportunidades para o engajamento, participação e interações entre as populações locais (stakeholders) e especialistas na condução dos processos de (re)desenho, (re)significação e transformação do espaço urbano. A cultura colaborativa/participativa na experimentação/intervenção dos espaços cotidianos - a criação de "possíveis comuns urbanos" - leva a apropriação destes espaços pela comunidade local.

Para tanto se faz necessário a estruturação de um processo sistêmico, sério e integrado - de forma colaborativa e participativa - que tenha uma coordenação técnica e multidisciplinar que represente, de fato, um consenso, consistência e coerência entre os distintos grupos de atores empresas, sociedade, governos e instituições (Anholt, 2013). Neste sentido, 
processos de transformação urbana e de reinvenção de identidades das cidades, tão representativos de economias neoliberais, poderiam se utilizar de ideias, conceitos e/ou subsídios "inovadores", conectando, de forma consistente e integrada, a Arquitetura + Design + Urbanismo. A inter-relação entre estes elementos, com projetos mediados por arquitetos, designers e urbanistas que dominem técnicas e metodologias participativas e inclusivas, guiados por lógicas menos "autorais" e mais holísticas - contrário ao "modelo Barcelona" - podem ajudar na adoção de alternativas mais participativas, solidárias, sustentáveis, e na elaboração de desenhos de cidade e de sistemas, planos e políticas urbanas mais ajustáveis, flexíveis, justos e equilibrados.

\section{Referências}

ANHOLT, Simon. Competitive Identity: The New Brand Management for Nations, Cities and Regions. London: Palgrave Macmillan, 2007

BALIBREA, Mari Paz. Urbanism, culture and the post-industrial city: challenging the Barcelona model in Journal of Spanish Cultural Studies, vol $2, \mathrm{n}^{\circ} 2,2001$, pp 187-201

BOHM, David. On Dialog. London: Routledge, 1996

CÂNDIDA, Simone. Pequena África, roteiro em homenagem ao continente, ganha novas atracões in O Globo. Rio de Janeiro, 2006. Disponível em https://oglobo.globo.com/rio/pequena-africa-roteiro-em-homenagem-aocontinente-ganha-novas-atracoes-18964630

Companhia de Desenvolvimento Urbano da Região do Porto do Rio de Janeiro. Circuito Histórico e Arqueológico da Celebração da Herança Africana. Disponível em http://portomaravilha.com.br/circuito/

Companhia de Desenvolvimento Urbano da Região do Porto do Rio de Janeiro. Porto Maravilha: permanências e mudanças. Disponível em http://www.portal2014.org.br/midia/site/1-22112011160951Alberto\%20Gomes\%20Silva\%20\%20Assessor\%20Especial\%20da\%20CDURP 
\%20\%20Cia.\%20Des.\%20Urbano\%20da\%20Regiao\%20Porto\%20do\%20Rio\% 20de\%20Janeiro.pdf

DA ROCHA E SILVA, Ana Beatriz Ferreira. Spectacular architecture, identity crisis, cultural politics and the reinvention of the significance of museums of modern art. PhD Thesis. Chelsea College of Art \& Design. University of the Arts London. London, 2011, pp 119-135

DA ROCHA, Ana Beatriz; REIS, Paulo. 'Rio Cidade Olímpica' e a construção de uma (nova) imagem para a Zona Portuária do Rio de Janeiro in Revista Thésis, vol 4, 2017. A ser publicado em http://www.thesis.anparq.org.br/

DA ROCHA, Ana Beatriz; REIS, Paulo. Culture as a mega-event how do heritage and local identity fit in the cosmopolitan image of the city? in: Cooper, F.; Greene, M.; Machado, D.; Scheerlinck, K; Schooljans, Y. ADU2020 Creative Adjacencies. Faculty of Architecture KU Leuven; Facultad de Arquitectura, Diseño y Estudios Urbanos, PUC-Chile: Ghent, 2015, pp 285-295

DA ROCHA, Ana Beatriz; REIS, Paulo. O processo de gentrificação do modo de vida dos Cariocas: o caso dos quiosques da orla da praia de Copacabana in: CinCci - IV Colóquio Internacional sobre o Comércio e Cidade: uma relação de origem, 2013. Disponível em http://www.labcom.fau.usp.br/wpcontent/uploads/2015/05/4_cincci/038-rocha.pdf

DA ROCHA, Ana Beatriz; REIS, Paulo. Crises, cultura e inovação como agentes no processo de regeneração urbana de centros urbanos in III Seminário Internacional URBICENTROS. Universidade Federal da Bahia, Salvador, 2012. Disponível em: http://www.ppgau.ufba.br/urbicentros/2012/?page_id=159

DAVENPORT, Thomas. Ecologia da Informação. São Paulo: Futura, 1998

DODD, Dianne. Barcelona: the making of a cultural city in Miles, Malcolm; Hall, Tim; Borden, Iain (eds). The City Cultures Reader. London: Routledge, 2004, pp 177-182. 
GIANNELLA, Letícia Carvalho. A produção histórica do espaço portuário da cidade do Rio de Janeiro e o projeto Porto Maravilha in Espaço e Economia, $\mathrm{n}^{\mathrm{o}} 3,19$ Dezembro, 2013. Disponível em: http://espacoeconomia.revues.org/445

Global Agenda Council on The Future of Cities. Top Ten Urban Innovations. World Economic Forum, 2015. Disponível em: http://www3.weforum.org/docs/Top_10_Emerging_Urban_Innovations_r eport_2010_20.10.pdf

GUimarÃes, Roberta Sampaio. A utopia da Pequena África: projetos urbanísticos, patrimônios e conflitos na Zona Portuária. Rio de Janeiro: FAPERJ/ FGV editora, 2014

HARVEY, David. The condition of postmodernity: an enquiry into the origins of cultural change. London: Blackwell, 1989

JACOBS. Jane. The death and life of great American cities. New York: Random House, 1961

KOTLER, Philip; GERTNER, David. Country as brand, product, and beyond: A place marketing and brand management perspective in Journal of Brand Management, vol 9, $\mathrm{n}^{\circ}$. 4-5, 2002, pp 249-261

NONAKA, Ikujiro; TAKEUCHI, Hirotaka. Criação de conhecimento na empresa: como as empresas japonesas geram a dinâmica da inovação. Rio de Janeiro: Campus, 1997

O Globo. Excesso de quiosques comprometerá a Orla Conde. Rio de Janeiro, 31 maio, 2016. Disponível em https://oglobo.globo.com/opiniao/excesso-de-quiosques-comprometeraorla-conde-21415165

ONU. Cidades terão mais de 6 milhões de habitantes em 2050, destaca novo relatório da ONU, 2014. Disponível em: https://nacoesunidas.org/cidades-terao-mais-de-6-bilhoes-de-habitantesem-2050-destaca-novo-relatorio-da-onu/ 
ONU. Cidades do Mundo. Atual modelo de urbanização é insustentável, 2015. Disponível em: https://nacoesunidas.org/atual-modelo-deurbanizacao-e-insustentavel-onu-habitat-relatorio/

RIVAS, Miguel. Innovative Place Brand Management, Re-Learning City Branding. URBACT-City Logo final report, 2015. Disponível em urbact.eu/file/9982/download?token=ZYFA-h2E

SCOTT, Allen J. As cidades da terceira onda in: Pacheco, S e Machado, M. (orgs.) Globalização, políticas públicas e reestruturação territorial. Rio de Janeiro: 7 Letras, 2012

VAZ, Lilian Fessler. A 'Culturalização' do Planejamento e da Cidade in Cadernos PPG-AU/FAUBA. Salvador: UFBA, 2004, pp 31-42

VILLA, Nicola; MITCHELL, Shane. Connecting Cities Achieving Sustainability Through Innovation. White paper in Cisco Internet Business Solution Group, 2010. Disponível em:

http://www.cisco.com/c/dam/en_us/about/ac79/docs/innov/Connecting _Cities_Sustainability_Through_Innovation_IBSG_1021FINAL.pdf 


\section{Como citar}

DA ROCHA, Ana Beatriz; REIS, Paulo. Como a Arquitetura + Design + Urbanismo contribuem no / para o processo de (re)invenção de identidades das cidades? Arcos Design. Rio de Janeiro: PPD ESDI - UERJ. Edição Especial Outubro 2017, pp. 127146. Disponível em: [http://www.e-publicacoes.uerj.br/index.php/ arcosdesign]

DOI 10.12957/arcosdesign.2017.30945

\section{(c) (i) () (2)}

A Revista Arcos Design está licenciada sob uma licença Creative Commons Atribuição - Não Comercial - Compartilha Igual 3.0 Não Adaptada. 